Intervenção em Saúde do Trabalhador

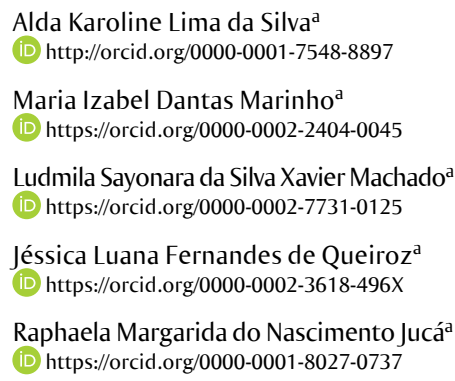

Os autores declaram que o trabalho não foi subvencionado e que não há conflitos de interesses.

Os autores informam que o trabalho não foi apresentado em eventos científicos e que não foi baseado em dissertação ou tese.

\section{Assédio moral no trabalho: do enfrentamento individual ao coletivo}

\author{
Mobbing at work: from individual to collective confrontation
}

\section{Resumo}

Objetivo: relatar uma experiência de acolhimento de trabalhadores em um serviço escola de psicologia e apresentar os resultados obtidos por meio de ações desenvolvidas para o enfretamento, individual e coletivo, de assédio moral no trabalho. Métodos: relato de intervenção vivenciada em serviço de psicologia. A intervenção se deu em dois momentos: 1) acolhimento terapêutico individual do caso inicial, 2) acolhimento em grupo. O atendimento individual ocorreu em oito encontros e o de grupo, constituído por sete trabalhadores, em nove encontros. A análise se deu com a leitura de prontuários e diários e de reuniões para discussão e convergência dos conteúdos emergidos. Resultados: foram sistematizados dois dispositivos de análise, o assédio ao indivíduo e o assédio ao grupo. O primeiro apontou as reelaborações do trabalhador frente ao fenômeno. O segundo promoveu o fortalecimento enquanto grupo, por meio da partilha e da construção coletiva dos meios de enfrentamento. Conclusão: reafirma-se a importância do acolhimento ao assediado e/ou testemunhas como modo inicial para enfrentar o assédio, seguido da necessidade de espaços coletivos para ressignificação dos efeitos psicossociais que o assédio moral produz ao trabalhador e ao seu trabalho.

Palavras-chave: assédio moral no trabalho; práticas de acolhimento e enfrentamento; fortalecimento do coletivo.

\begin{abstract}
Objective: to report an experience of welcoming workers in a psychology school service and to present the results obtained through actions undertaken for the individual and collective confrontation of mobbing at work. Methods: report of intervention experienced in a psychology service. The intervention took place in two moments: 1) initial case individual therapeutic welcoming, 2) group welcoming. The individual care was provided in eight meetings. The group, consisting of seven workers, in nine care meetings. The analysis was carried out with the reading of medical records and diaries, as well as by meetings for discussion and convergence of the emerged contents. Results: two analysis devices were systematized: individual mobbing and group mobbing. The first one pointed out the worker's re-elaborations due to the phenomenon. The second promoted the group strengthening while it shared and constructed collectively its means of confrontation. Conclusion: the authors reaffirm the importance of welcoming the mobbed workers and/or their witnesses as a starting point to deal with mobbing It must be followed by collective spaces to re-signify the psychosocial effects of mobbing on the workers and their work.
\end{abstract}

Keywords: mobbing at work; welcoming and confrontation practices; collective strengthening. 


\section{Introdução}

Tema de importância jurídica, social e psicológica para o mundo do trabalho, o assédio moral no trabalho requer mais estudos, afirmam estudiosas da área como Glina e Soboll ${ }^{1}$; mesmo este tipo de violência não sendo um fenômeno novo e, provavelmente, praticado desde o início das relações de trabalho ${ }^{2}$. Sobre esta temática, antiga e repercussiva, pretende-se apresentar uma análise do processo de enfrentamento desse fenômeno sob a ótica de trabalhadores assediados, por meio de um relato de experiência das ações desenvolvidas com servidores públicos vítimas de assédio moral no trabalho.

Neste estudo, concebemos o assédio moral no trabalho como um fenômeno que se estabelece a partir de atos de agressividade e humilhação ocorridos de forma processual e repetitiva, direcionada a uma ou mais pessoas, visando isolá-la e prejudicá-la em seu contexto de trabalho de forma intencional, podendo acontecer de forma horizontal (entre pares de mesmo nível hierárquico), vertical descendente (de nível hierárquico superior para outro inferior) ou ascendente (de nível hierárquico inferior para outro superior) ${ }^{3}$.

É uma forma específica de violência no contexto do trabalho, com caráter predominantemente psicológico $^{4}$. Dependendo do país e cultura, esse fenômeno possui outra denominação, como mobbing ou psicoterror, entre outros ${ }^{5}$. Sua compreensão e discussão no âmbito internacional têm Leymann ${ }^{6}$ e Hirigoyen ${ }^{7}$ como autores de referência. No Brasil, a discussão surgiu de forma mais sistematizada na academia a partir das pesquisas realizadas por Margarida Barreto $^{8}$, que fomentou de forma significativa a propagação da temática e de novos estudos ${ }^{3,4,9,10}$.

$\mathrm{O}$ assédio vem sendo gradativamente discutido como uma violência silenciosa que desestabiliza a vítima, agride a sua saúde, abala a relação de trabalho e contamina o ambiente laborativo, podendo levar ao dano pessoal e à incapacidade temporária ou definitiva para o trabalho $0^{5,7,8}$. Sendo praticado, na maioria das vezes, a partir de atos sutis e sistematizados, atingindo em especial o subjetivo da vítima e tornando complexa sua identificação, classificação e encaminhamento. Segundo Tolfo et al. ${ }^{4}$ o que torna essa identificação possível é a frequência e continuidade dos atos de violência.

Soboll ${ }^{3}$ apresenta dois conceitos para a compreensão do assédio: assédio moral propriamente dito (relações interpessoais), e o assédio organizacional (políticas de gestão do trabalho). Franco et al. ${ }^{11}$ consideram o assédio como uma das mais significativas formas de violência psicológica no atual cenário de trabalho precarizado. Destacam ainda que, independentemente do tipo de assédio a que o sujeito está exposto, configura-se uma situação potencialmente adoecedora. Geralmente tem início de forma lenta e gradual, o que o torna um modo de violência invisível.

De acordo com Vieira e colaboradores ${ }^{10}$, o fenômeno geralmente é apresentado sob o olhar da psicologização ou da judicialização, mas consideram que o assédio moral possui dimensões mais complexas, que estão além das questões "morais" do tipo ausência de cooperação, autoritarismo, atitudes sem limites éticos, elencadas para justificar a prática na esfera psicológica. Consideram que estes são na verdade valores estimulados pelo próprio modo de organização do trabalho. Aqui o assédio se amplia para além das relações interpessoais, configurando-se em um assédio ao próprio trabalho.

O assédio moral é um processo multicausal com diferentes abordagens, que ora estão focalizadas no indivíduo ora no contexto ou, ainda, em ambos, já que não se trata de um viés, mas de métodos e abordagens distintos ${ }^{12}$. Assim, a abordagem psicológica será mais centrada sobre o indivíduo, enquanto uma abordagem sociológica será mais voltada para o contexto ${ }^{13}$. Suas consequências atingem não só a vítima, mas também a organização de trabalho (produtividade, rotatividade e desmotivação) e a sociedade como um todo (índices de desemprego, danos do adoecimento e conflitos familiares) ${ }^{14}$. Diante deste cenário, que mostra o assédio moral no trabalho como uma violência cada vez mais possível e que produz consequências em diversos âmbitos, quais intervenções podem ser realizadas para enfrentá-lo? Glina e Soboll ${ }^{1}$, em seus estudos, apontam três níveis de intervenção: entre os(as) assediadores(as) e assediados(as); com a equipe e/ou os colegas de trabalho; e nas organizações. Refletem quanto à sua resolutividade e dizem que as intervenções geralmente são realizadas de forma pontual e/ou esporadicamente. A intervenção deste relato atingiu de forma parcial o primeiro nível trazido pelas autoras, ou seja, se deu entre os trabalhadores assediados.

As intervenções desenvolvidas por meio de grupos de enfrentamento apresentam-se como uma estratégia que possibilita impactar o coletivo. Elas têm sido usadas de forma frequente na área da psicologia devido à sua potencialidade e ao compartilhamento de vivências, que colabora para a [des] individualização da dificuldade e do sofrimento. Os grupos de apoio a trabalhadores assediados têm se mostrado uma alternativa significativa no enfrentamento do assédio ${ }^{4}$.

Ao considerar a necessidade de produção de mais estudos interventivos no campo, este relato teve por objetivo compartilhar uma experiência de 
acolhimento de trabalhadores em um serviço escola de psicologia e apresentar os resultados obtidos por meio de ações desenvolvidas para o enfrentamento, individual e coletivo, de assédio moral no trabalho.

\section{Percurso metodológico}

Trata-se de um relato de uma intervenção vivenciada a partir da experiência de estágio em um serviço escola de psicologia, entre os anos de 2015 e 2016. Os participantes foram servidores públicos assediados moralmente no trabalho, de categorias profissionais diversas (guarda de trânsito, professor, guarda patrimonial, contador, gari, assistente administrativo e técnico de enfermagem) que, na época, eram cedidos para uma entidade civil sem fins lucrativos do Estado.

O trabalho desenvolvido foi marcado por dois momentos: atendimento individual a um trabalhador assediado, que por questões éticas será identificado como José; e intervenção em grupo, a partir da iniciativa de José em fortalecer seu coletivo de trabalho, também assediado moralmente.

Ressalta-se que as exigências éticas foram cumpridas. Todo sujeito que busca um serviço escola é devidamente orientado quanto à sua dinâmica. É solicitado a assinatura do Termo de Consentimento Livre e Esclarecido (TCLE), por meio do qual autoriza o uso dos resultados/intervenções para fins de ensino e divulgação. Os participantes da intervenção em grupo, que não ocorreu nas dependências do serviço escola, também foram orientados e solicitados a assinar o TCLE no primeiro encontro. Foi submetido ao comitê de ética e pesquisa da Universidade Potiguar, cujo parecer aprovado em abril de 2017 pode ser verificado pelo $\mathrm{n}^{\circ}$ 2.004.087.

\section{Caracterização da demanda e dos participantes}

José, servidor público, 60 anos, casado, um filho. Desejava um espaço em que encontrasse apoio para suportar a situação que enfrentava no trabalho. Buscou por iniciativa própria o serviço de psicologia, ao tomar conhecimento de que era oferecido o acolhimento em saúde do trabalhador (após assistir uma palestra sobre assédio moral no trabalho). Ele chegou ao serviço consciente que sofria assédio moral e já com o processo judicial em andamento.

Foram realizados oito encontros individuais durante quatro meses, com frequência semanal ou quinzenal. Cada atendimento teve duração de 50 minutos, cujos relatos foram registrados em sínteses e armazenados no prontuário do serviço. Como aporte teórico para a realização dos acolhimentos, foram seguidas as contribuições de autores do campo da psicologia social do trabalho e da saúde do trabalhador, cujo tema do assédio era a fonte de debate ${ }^{3,10}$.

Os atendimentos visaram, inicialmente, acolher, escutar e fortalecer o trabalhador para propiciar um espaço de reelaboração da experiência vivida a partir do assédio. Ao recontar sua história, oportunizava-se a ressignificação de sua situação e, assim, pensar possíveis modos de enfrentá-la. Para isso, nos atendimentos foram compartilhados materiais - em especial relatos de experiência - sobre o assédio moral no trabalho para que José se inteirasse da situação vivida. Outras abordagens foram desenvolvidas a partir da dinâmica dos atendimentos e da implicação de José: registros semelhantes a um diário para fixar as facetas do assediador, bem como para que pudesse expressar suas emoções e sentimentos; simulação de confronto com o assediador, com o intuito de possibilitar as reações frente ao júri, devido ao desejo da concretização da audiência de seu processo judicial; e a contação da história de vida a partir do trabalho, a fim de tornar evidente o papel do trabalho na vida de José.

Um dos encaminhamentos arrolados nos atendimentos foi a necessidade dos demais colegas de José usufruírem de um espaço de acolhimento. A partir da iniciativa do próprio participante, foi proposta a intervenção em grupo como meio de fortalecimento coletivo. Além de José, o grupo foi composto por mais seis colegas de trabalho, duas mulheres e quatro homens, servidores públicos há aproximadamente 10 anos, de ofícios diversos.

Os encontros foram realizados semanalmente, durante nove semanas, em uma instituição sindical parceira, com duração de cerca de 2 horas. O objetivo da intervenção foi fortalecê-los para o enfrentamento do assédio moral, notadamente para o processo judicial que moviam contra o assediador. O grupo teve três mediadores com formação em psicologia: uma facilitadora, outra como apoio e uma orientadora acadêmica que supervisionava semanalmente o processo.

Para fins de registros, foram utilizados diários de campo, ferramenta apropriada para o tipo de atividade e usual em pesquisas qualitativas ${ }^{15}$. Além disso, os participantes tinham receio de registros mais significativos por estarem enfrentando um processo judicial. As atividades em grupo tinham a perspectiva de análise do trabalho e os encontros foram "co-construídos", isto é, as temáticas a serem abordadas eram discutidas e deliberadas coletivamente. Diversas ferramentas, como documentários, textos e técnicas grupais foram adaptadas e desenvolvidas. 
O material registrado foi sistematizado e analisado por meio da leitura inicial de todo prontuário e diários, seguido de reuniões para discussão e convergência dos principais conteúdos emergidos no discurso dos participantes. Após análise, foi possível a sistematização de duas dimensões para apresentação dos resultados e discussão: o dispositivo do assédio no âmbito individual e o dispositivo do assédio pelo grupo. A partir disso, recorremos aos pressupostos teóricos do fenômeno do assédio moral no trabalho para construção da análise.

\section{Resultados e discussão}

Primeiramente, apresentamos detalhes do caso de José e os principais resultados do processo de acolhimento individual, seguido das análises do processo grupal.

\section{Síntese do caso}

José atuava como coordenador de uma entidade civil sem fins lucrativos do Estado em conjunto com mais dois coordenadores. O assédio foi desencadeado após o trabalhador se recusar a assinar um "cheque em branco", solicitação feita por um dos coordenadores da instituição. Sua recusa motivou o colega a difamá-lo, acusando-o de ladrão, isolando-o em seu próprio ambiente de trabalho e insultando-o publicamente.

Mesmo agindo com lisura e honestidade, José se sentiu prejudicado pelo ato de difamação cometido por seu assediador e, por este motivo, iniciou o processo judicial com o objetivo de provar a errônea acusação. Apesar de todo o sofrimento que o ambiente laboral gerava neste sujeito, ele sempre esteve persistente, confiante e consciente da sua própria atividade, não deixando de frequentar o trabalho um só dia.

Com o processo judicial em andamento, José conseguiu reunir seis testemunhas a seu favor; porém, as testemunhas compartilhavam do mesmo ambiente de trabalho e, por questões de hierarquia (subordinadas as coordenações), também passaram a ser assediadas moralmente. Uma de suas testemunhas, por exemplo, teve remuneração/gratificação retirada a mando do assediador.

No entanto, José sentia-se constantemente culpado pelo sofrimento que suas testemunhas também passavam, expondo em todos os encontros individuais a sua preocupação. À medida que se sentia fortalecido e determinado a continuar enfrentando o assediador, questionava-se sobre o que poderia fazer para minimizar o sofrimento dos seus colegas. Durante uma das sessões, foi feita a proposta de um atendimento em grupo com José e seus colegas. Ele prontamente aceitou e encaminhou as providências quanto à logística dos encontros (dia, horário, local e convite aos participantes).

\section{O assédio ao indivíduo}

Este dispositivo do assédio no âmbito individual aponta o caso do trabalhador assediado, suas reelaborações frente ao fenômeno, suas mudanças psíquico-afetivas e seus modos de reafirmar sua saúde pelo trabalho, mesmo diante de todo o processo de sofrimento advindo das situações vexatórias e humilhantes. O acolhimento individual teve como objetivo aliviar o sofrimento por meio de um espaço de escuta e acolhimento, como também fortalecer o trabalhador com a reelaboração da experiência vivida frente ao assédio e, com isso, desenvolver estratégias de enfrentamento.

O relato de José possibilitou tomar como primeira etapa para o acolhimento a identificação, com embasamento/fundamentação teórica, da situação vivida, evidenciando as características de assédio moral no trabalho: "nem cadeiras tenho mais em minha sala para ninguém conversar comigo [...] vou ao trabalho para cumprir a carga horária, minhas atividades diárias foram retiradas". Os autores Arruda, Nascimento e Pignatari ${ }^{16}$ relatam que as vítimas, em sua maioria, são isoladas do grupo de trabalho, hostilizadas e ridicularizadas, culpabilizadas e desacreditadas diante dos pares, o que reafirma a condição do assédio moral.

Com a identificação do processo de assédio moral e respaldo teórico, buscou-se compartilhar com José relatos de experiência e casos de assédio da literatura, com o objetivo de elucidar sobre tal fenômeno, bem como desenvolver possibilidades de enfrentamento. Partindo disso, o participante passou a identificar as ações do assediador, conforme compreendido nos estudos de Glina e Soboll ${ }^{1}$, Tolfo et al. ${ }^{4}$ e Arruda, Nascimento e Pignatari ${ }^{16}$ e a aplicar as orientações necessárias para não ser prejudicado em seu processo judicial, tais como evitar falar sem testemunhas presentes, tentar não ceder a provocações, gravar/registrar as ofensas e outras situações de assédio.

A determinação de José em enfrentar o assediador foi de extrema importância para a continuidade da intervenção. Sempre que solicitado a refletir sobre sua permanência nesse cargo, prontamente respondia "eu não renuncio, se eu renunciar estarei concordando que sou ladrão, é a minha dignidade". Premissa peculiar de José, pois o indivíduo assediado geralmente apresenta maior nível de depressão do que os que não sofreram esse tipo de violência, como evidenciaram Emadad et al. ${ }^{17} \mathrm{em}$ um estudo com 2.563 funcionários na Suécia entre os anos de 2000 e 2003. 
Tolfo et al. ${ }^{4}$ contam que a exposição ao assédio pode ter efeitos negativos na identidade e autoestima, além de ocasionar danos à saúde, tanto física quanto mental. Esclarecem, ainda, que os danos à saúde podem se manifestar através de ansiedade, alterações no humor, estresse, depressão e até suicídio. José trazia em seu discurso a "pressão" e associava a sua rouquidão ao sofrimento vivido, "já fiz todos os exames, e não há nada biológico, só pode ser psicológico, minha voz não era assim".

A pressão que sentia era provocada pelo ambiente de violência e pela ansiedade de concretizar a audiência constantemente adiada, trazida por José como um dos seus maiores incômodos diários: "Vivo à espera do dia da audiência". Foi então proposta uma reelaboração das atividades profissionais que desenvolveu durante sua vida. Verificou-se que trabalhar sob pressão sempre ocorreu em sua trajetória laboral, porém, nunca havia sofrido a pressão de ser assediado: "já trabalhei sob pressão, mas não essa pressão que sofro hoje". Diante disso, como estratégia para lidar com a espera pela audiência, foi feito uma simulação na sessão, de modo que José se sentisse frente ao assediador, sendo solicitado que expressasse como agiria e/ou o que perguntaria diante do assediador, ele respondeu: "calmamente perguntaria a ele porque age dessa forma, quais os motivos das acusações e de tantas ações".

À medida que os encontros se desenvolviam, José valorizava o espaço de escuta, relatava como sentia-se nos períodos entre os encontros: "estas duas últimas semanas me senti com menos pressão [...] durante os últimos dias parece que ele sossegou". Compartilhava cada nova faceta do assediador e como agiu diante delas, detendo-se às evidências. Procurava não compartilhar seu sofrimento com a família, pois esta insistia que ele desistisse do processo judicial, motivo que o levou a optar por não falar em casa sobre o assunto, levando toda sua angústia apenas para as sessões: "este é o espaço em que posso me expor".

Os atendimentos proporcionaram para José, além do espaço de escuta e acolhimento, a possibilidade de recontar sua história de vida pelo trabalho, oportunizando o resgate dos propósitos, motivações e seus modos de protagonizar o enfrentamento: "esse espaço me fez bem, me sinto melhor para enfrentar minha situação de trabalho". Era um meio de se afirmar frente à sua atividade de trabalho e, por conseguinte, de lutar pela sua saúde. José foi reconhecendo que ainda tinha voz, apesar da rouquidão apresentada e associada ao sofrimento vivido, à medida que se expressava e ressignificava sua relação com o trabalho.
José sentia tristeza ao ver seus colegas sofrendo violências diárias devido à posição que tomaram ("serem suas testemunhas"). Se culpabilizava pelo "mal" que estava fazendo aos colegas: "fico triste por ver que sofrem por minha causa". Quando questionado se percebia que era um motivador para essas pessoas, uma vez que sempre esteve determinado a enfrentar o sofrimento, afirmou que sim, dizendo: "sei que sou motivador para eles, mas fico triste em ver o que estão passando [...] gostaria de fazer algo por eles, afinal, o problema foi comigo". É inegável que os danos causados ao assediado e suas testemunhas pelo assédio moral no trabalho são nocivos a toda funcionalidade do local de trabalho ${ }^{18}$.

Do mesmo modo que foi possível intervir e promover acolhimento ao assediado, pode-se traçar uma intervenção em grupo. Alguns autores ressaltam a importância e necessidade de aconselhamento ou grupo de apoio às vítimas e testemunhas de situação de assédio moral no trabalho, dado que essas últimas também podem sofrer repercussões na saúde mental ${ }^{4,19,20,21}$. Após intervenção em grupo, ocorreu apenas mais um atendimento individual com o objetivo de obter uma devolutiva dos momentos realizados.

Salienta-se que o acolhimento individual compartilhado é essencial para qualquer vítima de assédio moral no trabalho; porém, tais estratégias de intervenção e acolhimento ainda são incipientes e nem sempre procuradas pelas vítimas. Glina e Soboll ${ }^{1}$ relatam que ainda não há muitas publicações disponíveis sobre assédio moral que tratem de experiências interventivas, reafirmando, assim, a necessidade de estudos nesse escopo temático.

\section{O assédio ao grupo}

A intervenção possibilitou a identificação do processo de assédio moral no grupo, promoveu o alívio do sofrimento por meio do compartilhamento das vivências e fortaleceu o grupo enquanto coletivo para o enfrentamento. No Quadro 1, é possível ver o desenvolvimento dos encontros. Tal quadro foi inspirado na tabela de planejamento de encontros de grupo de apoio desenvolvida por Tolfo et al. ${ }^{4}$

O encontro inicial cumpriu a função de acolher os trabalhadores por meio de um espaço de escuta e os auxiliou na compreensão do processo sistematizado do assédio moral e suas formas de violência. Os trabalhadores relataram as situações vivenciadas nos últimos meses na instituição, tornando possível a identificação do processo de assédio moral. Atitudes hostis como calúnia, difamação, humilhação e provocações foram pontuadas com frequência no espaço de trabalho. Ocorriam havia mais de seis meses, tempo esse identificado por Leymann ${ }^{\mathbf{6}}$ como necessário para estabelecimento do assédio moral. 
Quadro 1 Temas e atividades desenvolvidas nos encontros do grupo

\begin{tabular}{|c|c|c|c|}
\hline Encontro & Temática & Desenvolvimento & Fechamento \\
\hline Primeiro & $\begin{array}{l}\text { Acolhida e violência no } \\
\text { trabalho }\end{array}$ & $\begin{array}{l}\text { Acolhimento; apresentação; escuta; } \\
\text { levantamento da demanda coletiva e } \\
\text { expectativas. }\end{array}$ & $\begin{array}{l}\text { Reflexão sobre os relatos das situações } \\
\text { de violência e compartilhamento das } \\
\text { histórias; definição do objetivo do grupo; } \\
\text { estabelecimento do contrato psicológico. }\end{array}$ \\
\hline Segundo & Assédio moral & $\begin{array}{l}\text { Acolhimento; escuta; exposição do } \\
\text { documentário "A dor (in)visível”; discussão } \\
\text { sobre o documentário e sobre as características } \\
\text { do assédio moral a partir dos relatos do } \\
\text { encontro passado. }\end{array}$ & $\begin{array}{l}\text { Reflexão sobre a importância do espaço grupal; } \\
\text { definição da temática do encontro da semana } \\
\text { seguinte. }\end{array}$ \\
\hline Terceiro & $\begin{array}{l}\text { História de vida pelo } \\
\text { trabalho }\end{array}$ & $\begin{array}{l}\text { Acolhimento; relato da história de vida pelo } \\
\text { trabalho. }\end{array}$ & $\begin{array}{l}\text { Considerações sobre o compartilhamento das } \\
\text { histórias; reflexão sobre o lugar que ocupam } \\
\text { (representantes de uma classe); definição da } \\
\text { temática do encontro da semana seguinte. }\end{array}$ \\
\hline Quarto & $\begin{array}{l}\text { Historia de vida pelo } \\
\text { trabalho }\end{array}$ & $\begin{array}{l}\text { Acolhimento; escuta; retomada do encontro } \\
\text { anterior com foco na história de militância do } \\
\text { grupo; noção de trabalho bem feito. }\end{array}$ & $\begin{array}{l}\text { Reflexão sobre o papel que ocupam enquanto } \\
\text { militantes; reflexão sobre a noção de trabalho } \\
\text { bem feito; definição da temática da semana } \\
\text { seguinte. }\end{array}$ \\
\hline Quinto & Papéis & $\begin{array}{l}\text { Acolhimento; escuta; encenação da audiência } \\
\text { judicial a partir da troca de papeis; discussão } \\
\text { sobre o lugar ocupado por cada um na } \\
\text { atividade. }\end{array}$ & $\begin{array}{l}\text { Reflexão sobre a encenação e seus } \\
\text { desdobramentos; definição da temática do } \\
\text { encontro da semana seguinte. }\end{array}$ \\
\hline Sexto & Gestão & $\begin{array}{l}\text { Acolhimento; discussão sobre gestão e } \\
\text { liderança em uma instituição sindical. }\end{array}$ & $\begin{array}{l}\text { Reflexão sobre liderança; definição da temática } \\
\text { do encontro da semana seguinte; e solicitação } \\
\text { da atividade para próximo momento } \\
\text { Sobre o meu trabalho: } \\
\text { - O que gosto de fazer e faço? } \\
\text { - O que gosto de fazer e não faço? } \\
\text { - O que não gosto e faço? } \\
\text { - O que não gosto e não faço? }\end{array}$ \\
\hline Sétimo & Atividade de trabalho & $\begin{array}{l}\text { Acolhimento; compartilhamento das questões } \\
\text { apresentadas no encontro anterior. }\end{array}$ & $\begin{array}{l}\text { Reflexão sobre as respostas e os impactos } \\
\text { do assédio moral na atividade de trabalho; } \\
\text { definição da temática do encontro da semana } \\
\text { seguinte. }\end{array}$ \\
\hline Oitavo & Laços afetivos & Café da manhã coletivo no parque. & $\begin{array}{l}\text { Definição da temática do encontro da semana } \\
\text { seguinte. }\end{array}$ \\
\hline Nono & $\begin{array}{l}\text { Trabalho coletivo e } \\
\text { fechamento grupal }\end{array}$ & $\begin{array}{l}\text { Acolhimento; retrospectiva dos } \\
\text { encontros; discussão sobre coletivo de } \\
\text { trabalho. }\end{array}$ & $\begin{array}{l}\text { Feedback sobre o processo grupal; } \\
\text { encaminhamentos. }\end{array}$ \\
\hline
\end{tabular}

Para melhor compreensão das atitudes de assédio descritas pelos participantes, são apresentadas, no Quadro 2, as categorias de atitudes hostis definidas por Hirigoyen ${ }^{7}$ e os relatos dos trabalhadores a elas correspondentes. Hirigoyen ${ }^{7}$ identificou e sistematizou quatro categorias de atitudes hostis para caracterizar o assédio moral no trabalho: 1) deterioração proposital das condições de trabalho do assediado, que diz respeito às atitudes que dificultam, impedem e retiram o trabalho da vítima, induzindo-a ao erro ou prejudicando sua atividade de trabalho; 2) isolamento e recusa de comunicação, afastamento da vítima com intuito de isolá-la e impedir sua comunicação com os demais colegas; 3 ) atentado contra a dignidade, que são os atos de calúnia e difamação, discriminação, preconceito e humilhação; 4) praticar violência verbal ou física, agredir fisicamente, gritar, invadir a privacidade, danificar bens materiais, assediar ou agredir sexualmente. O modelo do quadro foi retirado do estudo de Tolfo et al. ${ }^{4}$

O grupo, como um todo estava em sofrimento e envolto em um processo de não submissão, pois submeter-se significava ocultar a dor, o sofrimento em si e os problemas de saúde. O grupo buscou fortalecimento para que o sofrimento decorrente das violências morais pudesse se constituir em gritos de advertência para busca de um trabalho digno e decente $^{22}$, de modo que todos pudessem exercer a (in)tolerância às práticas de abuso de poder exercidas pelo assediador. 
Quadro 2 Relação das vivências dos trabalhadores com as categorias de atitudes hostis de Hirigoyen ${ }^{7}$

\begin{tabular}{|c|c|}
\hline Categorias de atitudes hostis & Relatos ilustrativos dos participantes \\
\hline $\begin{array}{l}\text { Deterioração proposital das condições de } \\
\text { trabalho do assediado }\end{array}$ & $\begin{array}{l}\text { "Há } 6 \text { meses não recebo o adicional" - T2 } \\
\text { "Quando sou impedido de fazer o que tenho que fazer, vai minando minha capacidade } \\
\text { de ser humano"- T1 } \\
\text { "Eu desconfio que tem pontos de escuta nas salas, mesas etc"-T7 } \\
\text { "Saí das finanças como contador e passei a ser motorista, office boy dela"-T4 } \\
\text { "De técnico na saúde, passei a ser motorista, passei a ser cão de guarda"-T1 } \\
\text { "Machuca, não poder exercer o que desejo exercer"-T2 }\end{array}$ \\
\hline Isolamento e recusa de comunicação & "Colocou a tesouraria em outro lugar para que eu ficasse só" - T7 \\
\hline Atentado contra a dignidade & $\begin{array}{l}\text { "Ela dizia: eu sou um trator esmagador. Dizia que sabia o preço de todos nós”- T7 } \\
\text { "Mania de perseguição. Nossa vida pessoal veio à tona. A pessoa é capaz de tudo" - T3 } \\
\text { "Eu tinha que armar o palco. Já fui até cuspido (chorou). Já me deu vontade de jogar o } \\
\text { carro em um barranco" - T2 }\end{array}$ \\
\hline Violência verbal, física ou sexual & $\begin{array}{l}\text { "Hoje eu sinto nojo, ânsia de vômito por ter permitido que ela tivesse feito coisas } \\
\text { comigo"- T5 } \\
\text { "Minha filha tem um medo terrível, chora todas as vezes que a encontra" - T5 } \\
\text { "Provocava atrito, expunha as pessoas e sua vida pessoal”- T6 }\end{array}$ \\
\hline
\end{tabular}

Destacamos que as práticas de assédio moral só acontecem quando o assediador pensa ter o apoio ou a permissão, mesmo que implícita, para praticar o assédio. A complacência da organização e a prática dessa violência é validada pela falta de punição dos assediadores ${ }^{1}$. Neste caso, o processo de judicialização, não indiciado em primeira instância, foi o caminho encontrado pelo grupo frente à situação.

Na atividade em grupo, foi feita uma escolha sobre a ótica de análise do fenômeno, de modo a privilegiar a discussão sobre o trabalho e não somente sobre as consequências do assédio em si. Foi considerado que as problemáticas pertinentes ao trabalho estão inter-relacionadas ao seu modo da organização ${ }^{10}$ e a intervenção sobre elas precisa dar conta dessa relação. Evitou-se uma postura negligenciadora frente aos aspectos relativos ao trabalho. Para Vieira et al. ${ }^{10}$ :

Ao adotar como ponto de partida o trabalho concreto, tentamos expor os perigos de se cair em vieses comuns nas discussões em torno do problema do assédio moral, sendo os mais recorrentes a psicologização, a judicialização e a sociologização, quando apenas um fator é privilegiado em detrimento de outros que também fazem parte desse complexo problema. (p. 266)

O grupo, em muitos momentos, apontava a intencionalidade do agressor/coordenador nos atos de violência, caracterizando-o como uma pessoa sádica. No entanto, foi alertado que, mesmo considerando a probabilidade de que existam pessoas perversas, nesse cenário, não se pode esquecer de que essas ações, como exploram alguns autores ${ }^{7,11,14}$, acontecem quase sempre em um espaço de trabalho no qual o próprio "assediador" foi "nutrido" pelos modos atuais de configuração da organização e das relações do trabalho no mundo contemporâneo. Por isso, trabalhar com o assediador ou puni-lo não parece ser uma solução duradoura (embora necessária), já que são as configurações do trabalho atual que devem ser reconsideradas e transformadas.

\section{Considerações finais}

Este estudo foi além da iniciativa no campo da psicologia ao lançar mão de uma atuação que ampliou o espaço de acolhimento individual para o trabalho em grupo e ao utilizar métodos e técnicas de intervenção focados na análise do assédio pelo trabalho não apenas enfatizando a sintomatologia provocada pelo evento. Isso permitiu colocar em cena o trabalhador vítima do assédio de forma que pudesse ser acolhido e, ao mesmo tempo, protagonizar e fomentar espaços de debates e embates nesta arena política e ideológica que enfrenta no mundo do trabalho.

Como limite, pode-se destacar a dificuldade, enquanto equipe de um serviço escola, de atuar nas políticas institucionais da organização onde os eventos ocorreram, pois a demanda de atuação ficou restrita aos trabalhadores. Sabe-se que, onde o assédio estiver instalado nos aparatos institucionais, é preciso ir além do acolhimento no âmbito individual e grupal e adotar práticas que não legitimem qualquer tipo de violência ou conduta antiética no espaço laboral, o que envolve uma mudança em todo corpo de gestão.

Em decorrência das configurações atuais do mundo do trabalho e de suas contradições sociais, o assédio moral no trabalho se apresenta como parte integrante do modelo econômico e dos processos produtivos vigentes, visto que estes legitimam as violências nas relações de poder ${ }^{10}$. Nesse sentido, 
alertamos para a necessidade de se propiciar mais espaços coletivos para reflexão e elaboração destas experiências traumáticas e de ampliar a discussão para melhor compreender a manifestação do "trabalho assediado" que se materializa em determinadas formas de organização e modelos de gestão.

\section{Contribuições de autoria}

Lima, KSL contribuiu substancialmente no projeto, delineamento, levantamento de dados, análise e interpretação. Marinho, MID participou da elaboração do manuscritoe na sua revisão crítica. Machado, LSSX, Queiros, JLF e Jucá, RMN participaram da elaboração do manuscrito e de sua revisão crítica. Todos participaram da aprovação final da versão publicada e assumem igual responsabilidade por seu conteúdo.

\section{Referências}

1. Glina DMR, Soboll LA. Intervenções em assédio moral no trabalho: uma revisão da literatura. Rev Bras Saude Ocup [Internet]. 2012 [citado em 6 mar 2018];37(126):269-283. Disponível em: http://www. scielo.br/scielo.php?script $=$ sci_arttext\&pid $=$ S0303-

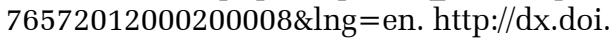
org/10.1590/S0303-76572012000200008.

2. Soboll LA, Miara T, Moscalewsky J. A questão da intencionalidade no assédio moral. Trab (En)Cena [Internet]. 2017 [citado em 5 mar 2018];2(2):317. Disponível em: https://sistemas.uft.edu.br/ periodicos/index.php/encena/article/view/3832.

3. Soboll LAP. Assédio moral/organizacional: uma análise da organização do trabalho. São Paulo: Casa do Psicólogo; 2008.

4. Albanaes P, Rodrigues KJR, Pellegrini PG, Tolfo RS. Intervenção em grupo de apoio psicológico a trabalhadores vítimas de assédio moral. Rev Psicol [Internet]. 2017 [citado em 20 fev 2018];35(1):61-96. Disponível em: http://www. scielo.org.pe/pdf/psico/v35n1/a04v35n1.pdf.

5. Caniato AMP, Lima EC. Assédio moral nas organizações de trabalho: perversão e sofrimento. Cad Psicol Soc Trab [Internet]. 2008 [citado em 20 fev 2018];11(2):177-192. Disponível em: http:// pepsic.bvsalud.org/pdf/cpst/v11n2/a04v11n2.pdf.

6. Leymann $\mathrm{H}$. The content and development of mobbing at work. Eur J Work Organ Psychol. 1996;5:165-184.

7. Hirigoyen MF. Mal-estar no trabalho, redefinindo o assédio moral. 3. ed. Rio de Janeiro: Bertrand Brasil; 2002.

8. Barreto MMS. Assédio Moral: a violência sutil análise epidemiológica e psicossocial no trabalho no Brasil [tese]. São Paulo: Pontifícia Universidade Católica de São Paulo; 2005.

9. Gosdal TC, Soboll LA, Schatzmam M, Eberle AD. Assédio moral organizacional: esclarecimentos conceituais e repercussões. In: Gosdal TC, Soboll LA. Assédio moral interpessoal e organizacional: um enfoque interdisciplinar. São Paulo: LTr; 2009. p. 33-41.
10. Vieira CEC, Lima FPA, Lima MEA. E se o assédio não fosse moral? Perspectivas de análise de conflitos interpessoais em situações de trabalho. Rev Bras Saude Ocup [Internet]. 2012 [citado em 22 fev 2018];37(126):256268. Disponível em: http://www.scielo.br/ scielo.php?script $=$ sci arttext\&pid $=$ S0303$76572012000200007 \& \bar{l} \mathrm{lng}=\mathrm{pt} \& \mathrm{nrm}=\mathrm{iso \& t} \operatorname{lng}=\mathrm{pt}$

11. Franco T, Druck G, Seligmann-Silva E. As novas relações de trabalho, o desgaste mental do trabalhador e os transtornos mentais no trabalho precarizado. Rev Bras Saude Ocup [Internet]. 2010 [citado em 2 mar 2018];35(122):229-248. Disponível em: http://www.scielo.br/scielo. php?pid=S0303-76572010000200006\&script $=$ sci abstract\&tlng $=$ pt.

12. Bradaschia CA. Assédio moral no trabalho: uma sistematização dos estudos sobre um campo em construção [dissertação]. São Paulo: Fundação Getúlio Vargas; 2007.

13. Rissi V, Monteiro JK, Cecconello WW, Moraes EG. Intervenções psicológicas diante do assédio moral no trabalho. Temas psicol [Internet]. 2016 [citado em 5 maio 2019];24(1):339-352. Disponível em: http://pepsic.bvsalud.org/pdf/tp/v24n1/v24n1a18. pdf

14. Elgenneni SMM, Vercesi C. Assédio moral no trabalho: implicações individuais, organizacionais e sociais. Rev Psicol Organ Trab [Internet]. 2009 [citado em 20 fev 2018];9(1):68-85. Disponível em: http://pepsic.bvsalud.org/scielo.php?script=sci_artt ext\&pid=S1984-66572009000100005

15. Frizzo CR. Diário de campo: reflexões epistemológicas e metodológicas. In: Sarriera JC, Saforcada ET. Introdução à psicologia comunitária: bases teóricas e metodológicas. Porto Alegre: Sulina; 2010. p. 169-187.

16. Arruda LP, Nascimento MP, Pignatari NDG. Assédio Moral no ambiente de trabalho. Rev Linhas Jurídicas [Internet]. 2012 [citado em 6 mar 2018];4(4):89-100. Disponível em: http://periodicos. unifev.edu.br/index.php/LinhasJuridicas/article/ viewFile/61/55 
17. Emadad R, Alipour A, Hagberg J, Jensen IB. The impact of bystanding to workplace bullying on symptoms of depression among women and men in industry in Sweden: an empirical and theoretical longitudinal study. Int Arch Occup Environ Health [Internet]. 2013 [citado em 9 mar 2018];86(6):709-716. Disponível em: https://www. ncbi.nlm.nih.gov/pmc/articles/PMC3722445/

18. Di Martino V. Violence at the workplace: the global response [Internet]. 2002 [citado em 9 mar 2018];9(1):4-7. Disponível em: http://citeseerx.ist. psu.edu/viewdoc/download?doi=10.1.1.452.1788\& rep $=$ rep1\&type $=$ pdf

19. Evangelista MS, Faiman CJS. Assédio moral no trabalho: abordagens ao tema pela academia, por sindicatos e por órgãos governamentais. Saúde, Ética \& Justiça [Internet]. 2015 [citado em $20 \mathrm{fev}$ 2018];20(2):43-56. Disponível em: https://www. revistas.usp.br/sej/article/view/119306/0

20. Soares LQ, Ferreira MC. Pesquisa participante como opção metodológica para a investigação de práticas de assédio moral no trabalho. Rev Psicol Organ Trab [Internet]. 2006 [citado em 9 mar 2018];6(2):85-109. Disponível em: https:// periodicos.ufsc.br/index.php/rpot/article/ view/1117

21. Mesquita AA, Silva AS, Bezerra HR, Fontinele TP, Neiva YP. Assédio moral: impacto sobre a saúde mental e o envolvimento com trabalho em agentes comunitários de saúde. Psicol Saúde [Internet]. 2017 [citado em 6 mar 2018];9(1):3-17. Disponível em: http://pepsic.bvsalud.org/pdf/rpsaude/v9n1/ v9n1a01.pdf

22. Comissão Econômica para a América Latina e o Caribe, Programa das Nações Unidas para o Desenvolvimento, Organização Internacional do Trabalho. Emprego, desenvolvimento humano e trabalho decente: a experiência brasileira recente [Internet]. Brasília: CEPAL/PNUD/OIT; 2008 [citado em 23 jun 2018]. Disponível em: https://repositorio. cepal.org/bitstream/handle/11362/28396/ S3310981E552008_es.pdf?sequence $=1$ 